American Journal of Immunology 4 (4): 51-65, 2008

ISSN 1553-619X

(C) 2008 Science Publications

\title{
AAV-Based Targeting Gene Therapy
}

\author{
${ }^{1}$ Wenfang Shi, ${ }^{2}$ Mingxia Yu and ${ }^{1}$ Qijun Qian \\ ${ }^{1}$ Laboratory of Gene and Viral Therapy, Eastern Hepatobiliary Surgical Hospital, \\ Second Military Medical University, 225 Changhai Rd, Shanghai, PR China \\ ${ }^{2}$ Department of Immunology, Tongji Medical College, \\ Huazhong University of Science and Technology, Wuhan, Hubei, PR China
}

\begin{abstract}
Since the first parvovirus serotype AAV2 was isolated from human and used as a vector for gene therapy application, there have been significant progresses in AAV vector development. AAV vectors have been extensively investigated in gene therapy for a broad application. AAV vectors have been considered as the first choice of vector due to efficient infectivity, stable expression and nonpathogenicity. However, the untoward events in AAV mediated in vivo gene therapy studies proposed the new challenges for their further applications. Deep understanding of the viral life cycle, viral structure and replication, infection mechanism and efficiency of AAV DNA integration, in terms of contributing viral, host-cell factors and circumstances would promote to evaluate the advantages and disadvantages and provide more insightful information for the possible clinical applications. In this review, main effort will be focused on the recent progresses in gene delivery to the target cells via receptor-ligand interaction and DNA specific integration regulation. Furthermore AAV receptor and virus particle intracellular trafficking are also discussed.
\end{abstract}

Key words: AAV, gene therapy, targeting

\section{INTRODUCTION}

AAV has been considered as a safe vector for gene transfer and has been involved in many clinical trials to treat metabolic abnormalities, hemophilia disease, Parkinson's disease and cystic fibrosis. AAV vectors have following advantages in gene therapy studies. (1) AAV vector is able to site specifically integrate into the host genome. Site specific integration of AAV doesn't activate the possible oncogenes and the inserted gene can be maintained for a relatively long-term in host cell genome and stably expressed in vivo ${ }^{[55,71,128]}$. Furthermore, selective genomic integration can be achieved via genetic modified AAV vectors ${ }^{[126]}$. (2) AAV capsids endure capsid modification and serotype swapping, which allows the AAV-mediated cell targeting delivery based on virus-host interaction. (3) $\mathrm{AAV}$ vectors show wide host spectrum and high infectivity for dividing and non-dividing cells. (4) AAV vectors also have advantages for solid cancers' application due to its small size, because of its high penetrability through the tumor stroma compared to other viral vectors. (5) AAV vector is low immunogenic. Most of the AAV serotypes are isolated from human; therefore immune response against the vector is relatively low and re-administration is possible due to low in vivo neutralizing antibody. However, AAV vector caused immune response was discovered in vivo by several groups. Heparin binding directed activation of cytotoxic T cells against AAV2 capsid, but not AAV8, was determined, which partially explained the liver toxicity in AAV2, not AAV8 mediated hemophilia treatment ${ }^{[15,102,53]}$. Moreover, Wang et al observed AAV2 induced in vivo capsid-specific cytotoxic T cells, but not AAV7 or AAV8. This CTL exerted the functional cytolytic effect on capsid-peptide loaded target cells, but not AAV2 vector-transduced hepatocytes ${ }^{[111]}$. Similarly, AAV2 capsid-specific cytotoxic $T$ cells only eliminate AAV2 vector transduced cells co-expressing AAV2 capsid in vivo. $\mathrm{Li}$ further pointed out that additional modification to AAV vectors may be required for further study for elicitation of cellular immune response ${ }^{[16]}$. (6) AAV vector is reported to be non-pathogenic. AAV2 have been reported to be associated with certain pathogenic processes without causing obvious severe diseases ${ }^{[64,83]}$. Some recent studies, however, have shown hepatocarcinoma induced in AAV-injected mice due to

Corresponding Author: Wenfang Shi, Laboratory of Gene and Viral Terapy, Eastern Hepatobiliary Surgical Hospital, Second Military Medical University, 225 Changhai Rd, Shanghai, 200438 Tel: (86)21-35030677 Fax: (86)21-35030677 
insertion with 6-kilobase region of chromosome $12^{[26]}$. The mechanism and cause for this phenomenon certainly requires further investigation.

AAV has a broad tissue tropism due to wide expression of AAV receptors. Targeting may be achieved through local injection to liver, brain and muscle. However, the most popular and convenient administration means in human or tested animal models is intravenous injection. Broad host spectrum limits AAV vector targeting delivery to specific tissues. Biodistribution study of different serotype AAV vectors post-intravenous administration showed that AAV DNA was detected in lymphocyte tissue, particularly in spleen with high frequency and concentration and also in other tissue including liver, brain, lung, heart, gallbladder, pancreas, colon, kidney, ovary, uterus etc. ${ }^{[68]}$. These data indicated the necessity to generate specific gene expression via AAV vector targeting delivery and to reduce side effect caused by nonspecific therapeutic gene production. AAV-based gene targeting therapy strategies can be briefly categorized into the following five types. (1) Local administration. (2) DNA integration. (3) Receptor-ligand interaction. (4) Small interference RNA. (5) Tissue specific promoter. (6) AAV engineered cytotherapy.

AAV receptor and co-receptor: AAV viruses infect the host cells via the interaction between viral capsid and cell surface. Heparin sulfate proteoglycan is reported to act as primary receptor for adeno-associated virus type 2 (AAV-2). Reported AAV2 co-receptors include alphaVbeta5 integrin ${ }^{[94]}$, fibroblast growth factor receptor 1 (FGFR-1) ${ }^{[75]}$ and hepatocyte growth factor (c-Met) ${ }^{[8]}$. There was an attachment of AAV-3 strain $\mathrm{H}$ to heparin, heparin sulfate and FGFR$1^{[8,75,94,95]}$. AAV1 and AAV3 have different tropism from AAV2, which indicates that these two serotypes AAV vectors infect cell via different entry. AAV5 has natural tropism to the lung, central nervous system, muscle and eye. Studies showed that expression of the platelet-derived growth factor receptor (PDGFR-alphapolypeptide) was highly correlated with AAV5mediated transduction. Further investigation confirmed the role of PDGFR-alpha and PDGFR-beta as receptors for AAV-5. The tropism of AAV-5 in vivo also correlated with the expression pattern of PDGFRalpha ${ }^{[24]}$. Some other group reported that AAV5 transduction was highly sialic acid dependent; however, AAV6 was either sialic acid dependent or in-dependent in tested cells. Moreover, AAV5 didn't inhibit AAV6 mediated gene transduction, although sialic acid played critical role in their gene transduction. All these data suggested that AAV5 and AAV6 used different entry pathway ${ }^{[84]}$. AAV1 and AAV6 use the alpha2,3 and alpha2,6 sialic acids that are present on $\mathrm{N}$-linked glycoproteins as primary receptors ${ }^{[117]}$. Heparin sulfate can both inhibit AAV2 and AAV3 gene transductions; however, the ID (50) of rAAV-3 was higher than that of rAAV-2. Furthermore, virus-binding overlay assays indicated that AAV-2 and AAV-3 bound different membrane proteins, which is the cause that AAV3 can transduce the haematopoietic cells ${ }^{[40]}$. The different transduction efficiency between AAV2 and AAV5 for air way epithelial cells suggested these two serotype AAV vectors may use the different receptor. Histological study showed that the apical membrane of airway epithelia cells generated abundant high affinity receptors for AAV5, less for AAV2. Genetic or enzymatic removal of sialic acid from the air way epithelial cell surface significantly inhibited the AAV5 binding and gene transfer, especially lectin specially binding of 2,3-linked sialic acid ${ }^{[108]}$. AAV4 binding required alpha 2--3 O-linked sialic acid, whereas AAV5 required N-linked sialic acid ${ }^{[107,108]}$. Soluble alpha 2-3 sialic acid was able to block both AAV4 and AAV5 transduction and alpha 2-6 sialic acid only was able to block AAV5 transduction. A $37 / 67-\mathrm{kDa}$ laminin receptor (LamR) was reported to be the cellular receptor for $\mathrm{AAV}^{[2]}$. LamR greatly contributes to AAV8 robust transduction in the cultured cells and mouse liver in vivo although heparin sulfate also plays partial role to AAV8 attachment and viral infection. Moreover LamR plays a role in transduction by three other closely related serotypes (AAV2, -3 and -9). AAV9 has preferential in vivo transduction in cardiac tissue compared to AAV8 ${ }^{[46,103]}$. AAV2, 4 and 5 were confirmed to transduce the salivary gland cells in vitro and in vivo, however, these three serotype AAV vectors are different from each other in receptor binding, indicating they directly attach, bind and enter different cell types due to the membrane molecule expression variations $^{[49]}$. There is no cross-activity among these three AAV serotypes. Taken all together, there is not only one specific molecule involved as a single receptor for any serotype AAV virus infection. So far, except AAV2, all the other serotype AAV receptors still are not very clear. Tropic characteristic investigation of each serotype can provide important information for targeting gene transfer.

AAV entry trafficking: AAV virus infection requires the viral attachment on the cell surface membrane, followed by clathrin-dependent/ independent internalization. Endosome acidification is the critical process for AAV gene transduction efficiency, which is associated with early to late endosome transition and proteasome degradation activity ${ }^{[52]}$. Bartlett described the detailed AAV2 intracellular 
trafficking by covalently conjugating fluorophores to AAV and monitoring entry by fluorescence microscopy. AAV2 particles were internalized rapidly by standard receptor-mediated endocytosis from clathrin-coated pits (half-time $<10 \mathrm{~min}$ ) and viral particle moved to nucleus and accumulated perinuclearly within $30 \mathrm{~min}$ after endocytosis. Furthermore, AAV particle release after internalization from early endosomes requires an acidic environment for penetration into the cytosol. Although the rescue of AAV in the host cell needs helper adenovirus, the escape of AAV from endosome and trafficking of viral particle to the nucleus are non-dependent of adenovirus infection $^{[7]}$. Endosome releasing and nuclear processing are the rate limitings for gene transfer. However, Xiao reported that the duration of AAV nucleus translocation from cytoplasm as intact particles was quickened after co-infection with adenovirus and this facilitated AAV nuclear entry and translocation was not blocked by the nuclear pore complex inhibitor thapsigargan, indicating that one or more adenovirus capsid proteins might be altering trafficking. Accordant with Bartlett's discoveries, escape from early endosomes did not seem to be affected by adenovirus co-infection ${ }^{[118]}$. Kux genetically incorporated eGFP into the adenoassociated virus capsid by replacement of wild-type VP2 with GFP-VP2 fusion protein to allow more specific direct visualization of viral trafficking ${ }^{[59]}$. The results showed that nuclear translocation was a slow and inefficient process compared to adenovirus coinfection, which is consistent with Xiao's report. GFPtagged AAV particles can be applied for the studies of viral intracellular trafficking and nuclear entry. Discoveries obtained through this system argued against an efficient nulear mechanism of intact AAV capsid and favored the occurrence of viral uncoating before or during nuclear entry. New studies showed that Notch1 played a significant role in intracellular trafficking of recombinant adeno-associated virus type 2 (rAAV2) ${ }^{[80]}$. In the absence or low-level expression of Notch1, only binding of virus was found on the cell surface and internalization was impaired. However, increased Notch1 expression in these cells allowed efficient perinuclear accumulation of labeled capsids. Dynamin level were found not to be different, however, blocking dynamin function abrogated AAV2 transduction in cells over-expressing full-length Notch1 but not those cells expressing intracellular Notch1.

Targeting gene delivery: Local Administration: Local administration such as intramuscular, intra-tumor injection and microfusion can be performed for superficial tumor and tissue specific deficiency. Brain, muscle and liver are the most easy target tissues for local administration ${ }^{[22,30,73,112]}$. Inherited metabolic disease mucopolysaccharidosis type I (MPS I) was from the deficiency of alpha-L-iduronidase (IDUA), which is strictly expressed in the brain tissue. To target gene therapy to the CNS, recombinant AdenoAssociated Viral (AAV) vectors carrying IDUA sequence were administered to MPS I mice via injection into cerebrospinal fluid and this intrathecal administration of AAV-IDUA effectively delivered vector to brain cells with minimal invasion ${ }^{[12]}$. Muscle could be another target for local gene transfer therapy. Hoffman's study showed that gene transfer to skeletal muscle did not break tolerance achieved by liverderived expression ${ }^{[44]}$, indicating that muscle has its own privilege as a target tissue. Subretinal injection obtained the sufficient gene expression localized in retinal ganglion cells with modified AAV incorporating a Chicken Beta-Actin (CBA) promoter and the woodchuck hepatitis posttranscriptional regulatory element $^{[61]}$. Adeno-associatd vectors carrying the GFP driven by $\mathrm{CBA}$ promoter as a tracer and $\mathrm{U} 6$ promoter controlling small hairpin RNA targeting alpha-CaMKII (AAV-shCAM) were microfused into the rat hippocampus. The localized GFP expression was achieved and local alpha-CaMKII expression was significantly reduced as well ${ }^{[74]}$. Targeting delivery via local administration can only be achieved in limited situations such as muscle, skin, air way, brain or joint.

Gene targeting via DNA integration: High frequencies of gene targeting can be achieved in mammalian cells transduced by recombinant AdenoAssociated Virus (rAAV) vectors ${ }^{[79,81,119,123,128]}$. Gene therapy is to replace the abnormal gene with normal gene to maintain the sufficient protein production and function in the mutant cells via non-specific or specific integration. The ideal way is to correct the mutation via homologous recombination or reverse mutation, allowing the normal gene expression. Major efforts in the field are aimed towards targeting vector integration to specific sites in the host genome. Integration targeting to homologous chromosome sequences has been observed in vitro and in vivo. AAVS1 locus (19q13-3-qter) was originally considered as AAV2 integration site ${ }^{[33,51,97]}$. Studies have shown that 510nt region at the 5' end of AAVS1 DNA was responsible for directing AAV chromosomal integration signal. Giraud et al. ${ }^{[33]}$ also indicated that chromosomal integration locus may be involved in the genomic instability due to the unusual degree of DNA heterogeneity in the recovered vector associated with AAVS1. Muscle is the most widely targeted tissue to 
AAV2 owing to not only local administration but also genomic DNA targeting. Slow skeleton troponin $\mathrm{T}$ gene (TNNT1) is closely linked with AAVS1 locus and AAV DNA integration in muscle cells results in TNNT1-AAV junction, suggesting muscle is the natural target tissue for latent AAV infection ${ }^{[28]}$. Therefore there are numbers of clinical trials such as inherited diseases and hemophilia, based on AAV2 mediated gene transduction in muscle via gene transfer therapy. However, phenotypic alterations of AAV2-transduced muscle fiber cells may occur and further investigations are needed. Miller et al introduced AAV2 vector containing LacZ gene fragment into the mouse with nuclear-localized $4 \mathrm{bp}$-deleted lacZ mutant gene and achieved the precise correction of LacZ gene ${ }^{[67]}$. Although there are more progresses in DNA integration after the studies have been focused on integration via AAV2. However, this integration might increase the genome instability and cause the possible oncogene activation and oncogenesis. Miller reported that integrated AAV vectors were associated with chromosomal deletions and rearrangements which were frequently located on chromosome 19, while there were no such instabilities at the wild-type AAV integration site $^{[66]}$. In 2004, McCarty pointed out in his review that AAV integration in any context was inefficient and that the persistence of AAV gene delivery vectors in tissues was largely attributable to episomal genomes ${ }^{[63]}$. Based on widely known conception that Rep78/68 nonstructural proteins are responsible for AAV DNA integration at Rep Binding Site (RBS) on AAVS1, recent discovery showed that TRP-185, TRA RNA loop binding protein, bound to AAVS1 DNA and suppressed AAV DNA integration at AAVS1 RBS. TRP-185 was shown to change the specificity of DNA integration from AAVS1 RBS to a downstream region ${ }^{[71]}$. Human hematopoietic cells were co-infected with Rep78 and GFP expressing adenoviruses to study the DNA integration mediated by Rep78. Among all the analyzed integration sites, 30\% vector integrations are at AAVS1 RBS and $90 \%$ sites are mediated by Ad-ITR ${ }^{[113]}$. Accordantly, Feng et al found out that there were three Rep Binding Elements (RBE) in the AAV genome, two are in the inverted terminal repeats and one in newly discovered region encompassing the viral p5 promoter. RBE located in ITR was more efficient and specific than p5 RBE in Rep-dependent DNA integration ${ }^{[13]}$. AAV integration provides the genomic DNA targeting, however, the random insertion/integration occurs in parallel. More specific AAV DNA integration and gene targeting requires the Homologous Recombination (HR) pathway, as RNAi induced HR-involved gene silencing abolished stable long-term transgene expression $^{[104]}$. Homologous recombination allows efficient, high-fidelity, non-mutagenic gene repair in a host cell. Integration not only provides the stable, longterm transgene expression, but also induces human tumor cell phenotype alteration ${ }^{[109]}$. AAV DNA integrated HeLa cells have been investigated for cell growth rate, capacity of colony formation and sensitivity to genotoxic agent and cytolytic effect of parovirus H-1. Reduced growth rate, capacity of colony formation and cytolytic effect to parvovirus $\mathrm{H}-1$ were observed and increased sensitivity to genotoxic agents. All these effects were independent on number of integration DNA, furthermore the integration was preferentially located on chromosome 17 not 19 . However, some other integrations may cause cell transformation as reported that hepatocaricnoma causing integration was located in chromosome $12^{[26]}$. Therefore integration is dual-edge sword and specific integration site should be created and clarified. More further investigation on AAV DNA genome integration is required for more secure and stable transgene expression and satisfactory therapeutic effects. Mechanism for DNA integration or recombination should be investigated for this purpose as well.

Receptor-ligand interaction: All the AAV vectors contain viral coat, which is capsid protein, therefore the most popular and profound progress in virus mediated targeting is mainly about the viral capsid modification. Receptor-ligand interaction mediated targeting gene delivery relies on the well-known target molecule such as cancer associated/related antigen. Computer technology based bio-informatics analysis predicts the candidate peptide bound to target molecules. Phage display libraries are applied for potential peptides screening binding to known/unknown target molecules. Bacteriophage (phage) evolved as bacterial viruses, but can be adapted to transduce mammalian cells through ligand-directed targeting to a specific receptor. AAVP provides superior tumor transduction over phage and that incorporation of inverted terminal repeats is associated with improved fate of the delivered transgene ${ }^{[36]}$. Peptide screening from phage peptide display library is the major means to discover peptides bound to target molecules. However, there are still some limitations restricting the obtainment of high effective targeting peptide. New technology should be explored for screening more specific and selective peptide for targeting molecules. Capsid modification based receptor-ligand interaction strategy is categorized into the following groups: (1) non- genetically modified AAV capsid, such as bi-specific antibody conjugated to capsid surface, (2) exogenous peptide genetic insertion 
modified capsid (mosaic capsid), (3) serotype capsid mixture (chimeric serotype capsid) and (4) serotype capsid and genome switch (transcapsidation).

Chemical conjugation modified viral capsid: Targeting-molecule conjugate can directly modify virion binding with re-targeted cells. The delivery specificity is based on the re-targeting molecule selectivity, such as antibody, targeting peptide. Bispecific antibody labeled adeno-associated virus exerted the alternative tropism and viral infectivity and tumor selectivity are increased ${ }^{[47,70,11,114]}$. These bispecific antibodies linked the virions together with the target cells and the virions are engulfed into the targeted cells ${ }^{[47]}$. Yang engineered a recombinant AAV virion carrying the chimeric capsid protein with the variable region of a single-chain antibody against human CD34 molecules, a cell surface marker for hematopoietic stem/progenitor cells. And this recombinant AAV virion achieved an increased preferential infectivity in CD34+ human myoleukemia cell line KG-1, which is normally refractory to rAAV transduction ${ }^{[121]}$. Carlisle demonstrated that polymer-coating techniques could also be used to modify and retarget adeno-associated virus (AAV) types 5 and $8^{[12]}$. Efficient covalent attachment of poly-[N-(2-hydroxypropyl) methacrylamide] (HPMA) copolymer to AAV5 could only be achieved following modification of the virus with carbodiimide (EDC). Delivery of AAV5 genomes using polyethylenimine (PEI) and HPMA was efficient and provided absolute control of tropism and protection from antisera. However, the coating efficiency is very critical for the satisfactory targeting effect. Meanwhile the side effect of the coating agents such as PEI should be considered.

Genetic modified viral capsid: Mosaic capsid modifications contain the exogenous insertion introducing the possible interaction with target cells via inserted peptides or large molecules $^{[10,19,32,34,70,87,96,106,114,115]}$. Among the all applied insertion peptide and molecules, RGD4C is the most popular peptide for viral capsid modification to target the intergrin on the cellular surface majorly expressed on the tumor cells ${ }^{[32,34,54,87-90]}$. AAV mosaics revealed the selective and efficient transduction in targeted tumor cell ${ }^{[1,32,91]}$. The application of AAV2 mosaics with a protein A fragment inserted into their capsid, together with targeting antibodies, is a versatile method that allows the specific transduction of a wide array of cell types ${ }^{[32]}$. VEGF peptide, EGF peptide, FGF peptide, LH peptide have also been studied for their targeting function from different group $^{[6,23,72,87,99]}$.
However, all these mosaic capsid and bi-specific antibody modified capsid carry the native tropism and modification provides the viral alternative interaction with target cells. To precisely control and modulate the viral tropism, native tropism needs to be abrogated and only novel tropism from modification will be functional. Replicating adenovirus with mutated capsid proteins, in which the promiscuous adenovirus native tropism was abolished and a bi-specific adapter molecule to target the virus to the Epidermal Growth Factor Receptor (EGFR) was encoded ${ }^{[11]}$. Adenoassociated virus 2 natural tropism has been abrogated via double mutation in capsid at site 520 and 584 and a novel tropism was achieved via inserted RGD4C peptide proved by in vitro RGD-integrin mediated specific infectivity and heparin non-dependant infectivity ${ }^{[90]}$. Metabolically biotinylated AAV was produced via biotin peptide inserted into AAV capsid gene, such as serotype 1, 2, 3, 4 and 5. Due to high affinity and interaction between biotin and avidin, this strategy not only provides the unique platform for different serotype AAV purification, but also alters AAV tropism via biotin-mediated interaction with avidin-engineered cellular receptor ${ }^{[4]}$. Genetic modification on AAV vectors may overcome the barrier from AAV neutralizing antibody in vivo evidenced by AAV mutant's reduced affinity to neutralizing antibody ${ }^{[45]}$, indicating the AAV mutants not only introduce the selective transduction, but also make AAV re-administration feasible and rational in gene therapy application. Meheshri reported an approach involving the generation of large mutant capsid libraries and selection of Adeno-Associated Virus (AAV) 2 variants with enhanced properties including altered tropism, evasion from neutralizing antibody. This novel approach provides a high throughput selection process and directs to generate the "designer" gene delivery system with specific properties ${ }^{[60]}$. However, there are still some barriers of the genetic insertion modification of viral capsid in the achievement of targeting gene therapy, such as the specificity of inserted peptide, the titer of modified AAV vector and peptide binding ability.

Mixed serotype viral capsid: Serotype swapping among AAVs can endue different serotype AAV with new alternative tropism, which expanded the viral tropism and enhance the AAV mediated gene transduction as well ${ }^{[77]}$. Chimeric capsid contains the mixed capsid proteins from different serotype AAV or adenovirus, which was made by complementation with separate plasmids mixed at various ratios. During the vial assembly, the capsid proteins from different 
serotype were theoretically packaged into virion, depending on ratio of complementing plasmids. And moreover this mixed serotype capsid plasmids are up to five serotype $e^{[19,27,42,76,77,79,86]}$. Although the actual ratio of the each capsid from different serotype is difficult to determine, the data achieved strongly indicated that this strategy is very promising to generate sophisticated virus with multiple properties of different serotypes. Chimeric vector was produced by using the mixture of AAV2 and AAV1 capsid helper plasmids in the transfection process. Recombinant chimeric vector carried both parent serotype characters, such as purification by heparin sulfate column, gene transduction in both muscle (AAV1) and liver $(\mathrm{AAV} 2)^{[41]}$. Replacement of AAV2 capsid VP1 N terminus domain from amino acid 350 to 430 with corresponding domain of AAV1 capsid VP1 allowed the hybrid vector formation. In vitro characterization analysis of this hybrid vector showed that it had stronger heparin-sulfate binding affinity, higher stability of viral particles and more efficient gene transduction in muscle fiber cells, which indicated the hybrid vector achieved both tropism from parent vectors and may facilitate the initiation of clinical application study ${ }^{[43]}$. AAV vector achieved via this mixed serotype capsid transfection strategy may be difficult to be repeatable. Therefore it might not be ideal to develop this means for gene therapy or gene transfer. However, this strategy might play important role for viral structure studying and viral development analyzing.

Transcapsidation of different serotype capsid and AAV genome: AAV transcapsidation is a good method to study how the different serotype affects the gene transfer, gene transduction and gene expression. AAV2 is the best characterized serotype and served as the archetype for AAV replication study. Due to the well knowledge of genetic/biochemical properties of AAV2 and the host cell response to the AAV2 ITR, AAV2ITR was first cross-packaged into the serotype AAV4 capsid and compared the transduction efficiency to AAV5 vector containing AAV5ITR genome. The experiments was unsuccessful because the ITRs were from different serotype ${ }^{[124]}$. More studies have been carried out by packaging AAV2ITR genome with different serotype capsids and gene transduction efficiency has been further analyzed. Through this strategy it was found that efficient transduction mediated by AAV8 was due to rapid uncoating of vector genome ${ }^{[3,46,101,113]}$. A drawback of this strategy is that the transencapsidated AAV2 ITR into AAV5 capsid vector suffered from low titer yield, because the trs of AAV5 is significantly different from the trs of
AAV1, 2, 3, 4 and 6 and Rep78/68 cannot efficiently nick or process the AAV5 ITR trs ${ }^{[18]}$. A further complication is that while the N-terminus of Rep mediates specific ITR binding, the $\mathrm{C}$-terminus appears to interact specifically with the capsid ${ }^{[50]}$. Therefore, an alternative strategy is required for generating higher titer cross-packaged virus. In order to study the role of serotype-specific shell on viral transduction, a more comprehensive study was performed to crosspackage AAV2 ITR flanked vector genome into the capsids of AAV1, 2, 3, 4 and 5 by engineering chimeric AAV genome containing different serotype capsid gene and AAV2 replication gene ${ }^{[76,77]}$. Of the five serotype vectors, only types 2 and 3 were efficiently purified by heparin-Sepharose column chromatography, illustrating the high degree of similarity between these virions. These data established a hierarchy for efficient serotype-specific vector transduction depending on the target tissue. These data also strongly support the need for extending these analyses to additional animal models and human tissue. The development of these helper plasmids should facilitate direct comparisons of serotypes, as well as begin the standardization of production for further clinical development. The efficiency of interaction between the hybrid Reps and the serotype-specific capsids is increased, producing titers of cross-packaged vectors similar to that of AAV2. Different serotype AAV vectors carry different tropisms, therefore mixture of different serotype AAV capsid protein may help providing the custom-designed AAV vector. As shown by ${ }^{[76]}$, different ratio of capsid mixture affected the virions assembly, physical titer and infectivity. And this approach may be of great significant value to the field of targeting gene therapy.

Neutralizing antibody may partially or completely block the vector mediated gene transduction when the same serotype vector is administrated. Therefore serotype swapping or cross-packaging capsid protein have shown to solve this barrier at different level ${ }^{[37]}$.

Taken together, all the currently available genetic modified AAV targeting vectors need to be improved not only with regard to the elimination of the wild-type AAV tropism and but also the enhancement of viral assembly efficiency and selective infectivity. A better understanding of trans-membrane internalization and intracellular trafficking will provide the route to develop the more effective AAV vectors. New methodologies made to tailor the tropism of AAV have improved the transduction and selectivity profiles. Novel modification strategies have resulted in unique AAV vectors characterized by unique capsid protein sequences that employ alternative receptors. 
Small interference RNA: RNAi is an evolutionarily conserved mechanism for silencing gene expression by targeted degradation of $\mathrm{mRNA}^{[5,14,56,65,120]}$. AAV vector generated small interference RNA resulted in stable inhibition of hepatitis B protein expression ${ }^{[31]}$. Cong et al reported that AAV vectors carrying anti-sense RNA and small interference RNA of TIMP-, respectively, suppressed a long-term TIMP-1 gene expression significantly in rat hepatic stellate cells due to chromosomal integration ${ }^{[20]}$. Viral vector generated short hair-pin RNA can induce the small interference RNA. Therefore duplex-DNA containing AAV8 based shRNA delivery vector has been shown the oversaturation of microRNA against hepatitis B virus, causing the mice dead, indicating that AAV vector is able to produce sufficient microRNA by minimizing the $\operatorname{dose}^{[35]}$. Han et al applied AAV vector encoding small interference RNA targeted to primer binding site, which is the HIV reverse transcription initiation site and complementary to the $3^{\prime}$ terminal nucleotides of tRNA (Lys,3). AAV encoding siRNA targeted to the PBS of HIV-1 inhibited virus replication effectively ${ }^{[39]}$.

Tissue-specific transcription: Tumor Specific Promoter (TSP) makes it applicable to initiate the targeting expression of interested genes in the specific tissues and cells ${ }^{[98]}$. Application of TSP is one of the oldest means ever used for targeting gene therapy and still being used widely. Human TERT is the most widely used tumor specific promoter. There are more TSPs applied in the preclinical study and clinical study as well, such as $\mathrm{AFP}^{[116]}, \mathrm{CEA}^{[9]}, \mathrm{CXCR}^{[54]}$, surviving $^{[29,127]}, \quad$ osteocalcin $^{[38,62]}$, RPE targeting promoter ${ }^{[98]}$. TSPs are more applied in cancer gene therapy such as hTERT, AFP. AAV has been reported to inhibit the promoter activity of some oncogene and viral gene including human papillomavirus type $16^{[25,93,122,125]}$. AAV Rep78 was confirmed to inhibit transcription initiation of the HPV-16 LCR by disrupting the interaction between TATA binding protein and the TATA box of the p97 core promoter ${ }^{[93,125]}$. AAV Rep 78, not Rep68, was shown to be able to inhibit the CREB-dependent transcription pathway, indicating that AAV may disturb the cyclic AMP response pathway in the viral infected cell. Thereafter, it is suggested that this AAV Rep78 protein might be used to treat for HPV-induced infection and cancer such as cervical cancer. Cucchiarini demonstrated the selective transferred gene expression in microglia and macrophage lineage mediated by AAV-derived vector containing cell-type-specific transcriptional element regulating interest gene $\operatorname{expression}^{[21]}$. Transcriptional targeting were achieved via a novel AAV-based system in which rAAV vectors were generated harboring a luciferase reporter gene under the control of 1.5-kb cardiac myosin light chain promoter fused to the CMV immediate-early enhancer $(\mathrm{CMV}(\mathrm{enh}) / \mathrm{MLC} 1.5)^{[69]}$. Chen reported the specific anti-cancer effect mediated by AAV2 vector encoding p53 gene driven by AFP promtoer in hepatoma cells ${ }^{[17]}$. Hypoxia responsive promoter has been applied for driving oncolytic virus replication according to the tumor hypoxia environment ${ }^{[58,92,82]}$. The hypoxiaresponsive promoter 5HREp, in which five copies of the Hypoxia-Response Element (HRE) enhance transcription, was employed to induce the expression of BCD (bacterial cytosine deaminase) under hypoxic conditions. However, cell-type-specific promoter or regulation elements have not been applied or investigated in AAV as widely as adenovirus. All these tissue specific expression regulation elements are to be applied in AAV mediated gene therapy studies as well. Low interested gene expression is the major barrier for the targeting transcription. Then how to increase the gene expression is an important issue for wide application of transcription targeting. Some elements which are able to enhance the promoter initiated transcription ability are under investigated as well. Inducible tissue specific transcription cassette and powerful post-transcription regulatory element have been reported and high selective and continuous gene expression was maintained for a long period of time.

AAV engineered cytotherapy: AAV vector engineered cells also can be applied for cytotherapy, such as hemotopoietc stem cells ${ }^{[57,85,100,110,128]}$. HSCs are easily accessible and can be readily delivered back to patients by autologous transplantation, which renders them as attractive targets for ex vivo gene therapy. The AdenoAssociated Virus (AAV) vectors have to date not been associated with any malignant disease and have gained attention as a potentially safer alternative to the more commonly used retroviral vectors for HSC gene therapy. There exists a conflicting data with regard to HSC transduction by AAV vectors. AAV transduced Dentritic Cells (DC) expressing cancer antigen were potent activator of CD8+ T cells, indicating these AAV engineered DC cells could be developed into a new DC-based tumor vaccine. Self-complementary AAV1 or AAV2 were able to transduce ex vivo conventional DC, LC, or pDC more efficiently than single strain AAV1 or AAV2. These self-complementary AAV vector exerted direct targeting to DC cells in vivo as well ${ }^{[105]}$. AAV2 transduced human keratinocytes in ex vivo culture were applied to generate transgenepositive recombinant skin (r-skin), using the organotypic epithelial raft culture system ${ }^{[1]}$. 
Present Obstacles for AAV vectors: Even though it has been widely accepted that AAV vector is nonpathgenic, there are still some research reports about the possible pathological alternations induced by this vector. Schimidt reported that AAV2-Rep78 protein mediated apoptosis is caspase-2 dependent in wild-type p53 and p53-dull human cells, the possible mechanism of apoptosis in part is due to DNA binding and ATPase/helicase activity of Rep 78 protein, not its endonuclease activity ${ }^{[83]}$. Human cytomegalovirus (HCMV) is considered as a competent helper for complete replication of AAV, similar with adenovirus and herpes simplex virus. Accumulation of AAV capsid antigen and infectious AAV were observed in fibroblast cells co-infected with CMV and AAV and there was a $24 \mathrm{~h}$ lag of AAV replication compared to AAVadenovirus co-infection. Furthermore the synergistic cytopathic effect was induced as well, indicating AAV contributing to CMV-induced pathogenicity ${ }^{[64]}$. Recent studies illustrated that both normal mice and mice with mucopolysaccharidosis VII (MPS VII) developed hepatocellular carcinoma (HCC) after neonatal injection of an AAV vector expressing b-glucuronidase. These four tumors were confirmed to carry the integrated AAV DNA located within a 6-kilobase region of chromosome 12. Random integration of AAV vector causing untoward event raises the concerns of further clinical application of AAV vectors and requires the more clear specific integration site.

Future of AAV vectors: Targeting gene therapy has been studied broadly and widely. Modifications of different gene therapy vector have been made and targeting gene delivery also has been obtained with a varied specificity. However, the present receptor-ligand interaction mediated targeting is mainly dependent on the known target molecules. Unfortunately there is no absolute tumor associated antigen found so far, which may limit the tumor target effectiveness. Meanwhile, peptides or protein molecules desired for tumor associated antigen targeting are obtained from phage display screening and computer analysis. The phage enrichment process affects the affinity screening results and meanwhile the same sequence peptide expressed on gene therapy vector might not bind to target protein with the same affinity as it is expressed on phage. Therefore some new technologies need to be developed to discover the high affinity peptide to the already know target molecules and potential unknown tumor related antigens. Using the character of wild type virus infectivity and replication in host cells, the tumor cell specific virus can be discovered by its natural tropism and replication. This technology not only provides the high selective ligand binding to the tumor cells but also provide the possibility to discover the new tumor associated antigens. The alternative tropism can be introduced for chimeric AAV via AAV serotype swapping. Not only these hybrid serotypes could achieve high efficiency of gene delivery to a specific targeted cell type, which can be better-tailored for a particular clinical application, but also serve as a tool for studying AAV biology such as receptor binding, trafficking and genome delivery into the nucleus. Along with the broader clinical trials, further basic virological investigations and immune response involvement, targeting gene transfer and targeting DNA integration are very critical for safe issues and better therapeutic effects. Site specific integration of AAV is the next generation vector development direction. And high throughput and fast selection process for peptide screening for directing to the target molecules and to discover more target antigens as well is another possible trend for AAV targeting gene therapy.

\section{ACKNOWLEDGEMENT}

We thank Dr. Zhang C. at University of Florida and Dr. Zhou Xiangjun at Shanghai Jiaotong Unvieristy for the improvement of English writing. The study was supported by Nature and Science Foundation of China (30772477).

\section{REFERENCE}

1. Agrawal, N., H. You, Y. Liu, M. Chiriva-Internati, J. Bremner, T. Garg, F. Grizzi, C. Krishna Prasad, J.L. Mehta and P.L. Hermonat, 2004. Generation of recombinant skin in vitro by adeno-associated virus type 2 vector transduction. Tissue Eng., 10: 1707-1715. http://www.liebertonline. com/doi:/abs/10.1089/ten.2004.10.1707.

2. Akache, B., D. Grimm, K. Pandey, S.R. Yant, H. Xu and M.A. Kay, 2006. The 37/67-kilodalton laminin receptor is a receptor for adeno-associated virus serotypes 8, 2, 3 and 9. J. Virol., 80: $\quad$ 9831-9836. $\quad$ http://jvi.asm.org/ cgi/content/abstract/80/19/9831.

3. Akache, B., D. Grimm, X. Shen, S. Fuess, S.R. Yant, D.S. Glazer, J. Park and M.A. Kay, 2007. A two-hybrid screen identifies cathepsins B and $\mathrm{L}$ as uncoating factors for adeno-associated virus 2 and 8. Mol. Ther., 15: 330-339. http://www.ncbi.nlm.nih.gov/pubmed/17235311. 
4. Arnold, G.S., A.K. Sasser, M.D. Stachler and J.S. Bartlett, 2006. Metabolic biotinylation provides a unique platform for the purification and targeting of multiple AAV vector serotypes. Mol. Ther., 14: 97-106. http://www.ncbi.nlm. nih.gov/pubmed/16624620.

5. Arsic, N., S. Zacchigna, L. Zentilin, G. RamirezCorrea, L. Pattarini, A. Salvi, G. Sinagra and M. Giacca, 2004. Vascular endothelial growth factor stimulates skeletal muscle regeneration in vivo. Mol. Ther., 10: 844-854. DOI: 10.1016/j.ymthe.2004.08.007.

6. Barbon, C.M., R.J. Ziegler, C. Li, D. Armentano, M. Cherry, R.J. Desnick, E.H. Schuchman and S.H. Cheng, 2005. AAV8-mediated hepatic expression of acid sphingomyelinase corrects the metabolic defect in the visceral organs of a mouse model of Niemann-Pick disease. Mol. Ther., 12: 431-440. http://cat.inist.fr/ ?aModele $=$ afficheN\&cpsidt $=17066788$.

7. Bartlett, J.S., R. Wilcher and R.J. Samulski, 2000. Infectious entry pathway of adeno-associated virus and adeno-associated virus vectors. J. Virol., 74: 2777-2785. http://jvi.asm.org/ cgi/reprint/74/6/2777.pdf.

8. Blackburn, S.D., R.A. Steadman and F.B. Johnson, 2006. Attachment of adeno-associated virus type $3 \mathrm{H}$ to fibroblast growth factor receptor 1. Arch. Virol., 151: 617-623. http://www.ncbi.nlm. nih.gov/pubmed/16195782.

9. Blumenthal, R.D., E. Leon, H.J. Hansen and D.M. Goldenberg, 2007. Expression patterns of CEACAM5 and CEACAM6 in primary and metastatic cancers. BMC Cancer, 7: 2. DOI: 10.1186/1471-2407-7-2.

10. Buning, H., M.U. Ried, L. Perabo, F.M. Gerner, N.A. Huttner, J. Enssle and M. Hallek, 2003. Receptor targeting of adeno-associated virus vectors. Gene. Ther., 10: 1142-1151. http://www. ncbi.nlm.nih.gov/pubmed/12833123.

11. Carette, J.E., H.C. Graat, F.H. Schagen, D.C. Mastenbroek, M.G. Rots, H.J. Haisma, G.M. Groothuis, G.R. Schaap, J. Bras, G.J. Kaspers, P.I. Wuisman, W.R. Gerritsen and V.W. Van Beusechem, 2007. A conditionally replicating adenovirus with strict selectivity in killing cells expressing epidermal growth factor receptor. Virology, 361: 56-67. http://cat.inist.fr/ ?aModele $=$ afficheN\&cpsidt $=18698813$.

12. Carlisle, R.C., R. Benjamin, S.S. Briggs, S. Sumner-Jones, J. Mcintosh, D. Gill, S. Hyde, A. Nathwani, V. Subr, K. Ulbrich, L.W. Seymour and K.D. Fisher, 2008. Coating of adeno-associated virus with reactive polymers can ablate virus tropism, enable retargeting and provide resistance to neutralising antisera. J. Gene. Med., 10: 400-411. http://www.ncbi.nlm.nih.gov/ pubmed/18220318.
13. Carr, J.M., A.J. Davis, F. Feng, C.J. Burrell and P. Li, 2006. Cellular interactions of Virion Infectivity Factor (VIF) as potential therapeutic targets: Apobec3g and more? Curr. Drug Targets, 7: 1583-1593. DOI: $10.2174 /$ 138945006779025356.

14. Chakraborty, C., 2007. Potentiality of small interfering RNAs (siRNA) as recent therapeutic targets for gene-silencing. Curr. Drug Targets, 8: $\quad 469-482 . \quad$ http://www.ncbi.nlm.nih. gov/pubmed/17348839?dopt=Abstract.

15. Chen, J., Q. Wu, P. Yang, H.C. Hsu and J.D. Mountz, 2006. Determination of specific CD4 and CD8 T cell epitopes after AAV2- and AAV8hF.IX gene therapy. Mol. Ther., 13: 260-269. http:// cat.inist.fr/?aModele $=$ afficheN\&cpsidt $=17580627$.

16. Chen, Y., W.C. Liu, H.Y. Qin and H. Han, 2007. Transcriptional activities of human fatty acid synthase promoter in breast cancer cells. Xi Bao Yu Fen Zi Mian Yi Xue Za Zhi, 23: 429-431. http://www.ncbi.nlm.nih.gov/pubmed/17488603.

17. Cheng, J., X. Leng and J. Peng, 2000. Construction of a hepatoma-targeting vector of adeno-associated virus containing human alpha-fetoprotein promoter and wild P53 gene in gene therapy of liver cancer. Zhonghua Yi Xue Za Zhi, 80: 461-463. http://www.ncbi.nlm.nih.gov/pubmed/11798803.

18. Chiorini, J.A., S. Afione and R.M. Kotin, 1999. Adeno-Associated Virus (AAV) type 5 rep protein cleaves a unique terminal resolution site compared with other aav serotypes. J. Virol., 73: 4293-4298. http://jvi.asm.org/cgi/content/abstract/73/5/4293.

19. Choi, J.W., W.S. Ahn, S.M. Bae, D.B. Lee and Y.W. Kim, 2005. Adenoviral P53 effects and cellspecific E7 protein-protein interactions of human cervical cancer cells. Biosens. Bioelect., 20: 2236-2243. http://www.ncbi.nlm.nih. gov/pubmed/15797321.

20. Cong, M., P. Wang, T.H. Liu, Y. Xu, Y. Lu, S.Z. Tang, X.M. Liu, B.E. Wang, J.D. Jia and H. You, 2006. Comparison between the suppression of tissue inhibitor of metalloproteinase-1 gene expression by recombinant adeno-associated virus carrying antisense RNA and small interfering RNA (siRNA) of TIMP-1 in rat hepatic stellate cells. Zhonghua Gan Zang Bing Za Zhi, 14: 742-747. http://www.ncbi.nlm.nih.gov/pubmed/17064467.

21. Cucchiarini, M., X.L. Ren, G. Perides and E.F. Terwilliger, 2003. Selective gene expression in brain microglia mediated via adeno-associated virus type 2 and type 5 vectors. Gene Ther., 10, 657-667. http://cat.inist.fr/ ?aModele $=$ afficheN\&cpsidt $=14680015$. 
22. Cunningham, J., Y. Oiwa, D. Nagy, G. Podsakoff, P. Colosi and K.S. Bankiewicz, 2000. Distribution of AAV-TK following intracranial convectionenhanced delivery into rats. Cell Transplant., 9: 585-594. http://www.ncbi.nlm.nih.gov/ pubmed/11144956.

23. De Bruin, K., N. Ruthardt, K. Von Gersdorff, R. Bausinger, E. Wagner, M. Ogris and C. Brauchle, 2007. Cellular dynamics of EGF receptor-targeted synthetic viruses. Mol. Ther., 15: 1297-1305. DOI:10.1038/sj.mt.6300176.

24. Di Pasquale, G., B.L. Davidson, C.S. Stein, I. Martins, D. Scudiero, A. Monks and J.A. Chiorini, 2003. Identification of PDGFR as a receptor for AAV-5 transduction. Nat. Med., 9: 1306-1312. http://www.ncbi.nlm.nih.gov/pubmed/14502277.

25. Di Pasquale, G. and S.N. Stacey, 1998. Adenoassociated virus rep78 protein interacts with protein kinase a and its homolog PRKX and inhibits CREB-dependent transcriptional activation. J. Virol., 72: 7916-7925. http://jvi. asm.org/ cgi/content/abstract/72/10/7916.

26. Donsante, A., D.G. Miller, Y. Li, C. Vogler, E.M. Brunt, D.W. Russell and M.S. Sands, 2007. AAV vector integration sites in mouse hepatocellular carcinoma. Science, 317: 477. DOI: 10.1126/science. 1142658 .

27. Du, L., M. Kido, D.V. Lee, J.E. Rabinowitz, R.J. Samulski, S.W. Jamieson, M.D. Weitzman and P.A. Thistlethwaite, 2004. Differential myocardial gene delivery by recombinant serotype-specific adeno-associated viral vectors. Mol. Ther., 10: 604-608. http://cat.inist.fr/ ?aModele $=$ afficheN\&cpsidt $=16096578$.

28. Dutheil, N., F. Shi, T. Dupressoir and R.M. Linden, 2000. Adeno-associated virus site-specifically integrates into a muscle-specific dna region. Proc. Natl. Acad. Sci. USA., 97: 4862-4866. http:/www.pnas.org/content/97/9/4862.abstract.

29. Feng, D., J. Chen, Y. Yue, H. Zhu, J. Xue and W.W. Jia, 2006. A 16bp rep binding element is sufficient for mediating rep-dependent integration into aavs1. J. Mol. Biol., 358: 38-45. http://www. ncbi.nlm.nih.gov/pubmed/16516232.

30. Fu, H., R.J. Samulski, T.J. Mccown, Y.J. Picornell, D. Fletcher and J. Muenzer, 2002. Neurological correction of lysosomal storage in a mucopolysaccharidosis IIIB mouse model by adenoassociated virus-mediated gene delivery. Mol. Ther., 5: 42-49. DOI: 10.1006/mthe.2001.0514.

31. Generali, D., S.B. Fox, A. Berruti, J.W. Moore, M.P. Brizzi, N. Patel, G. Allevi, S. Bonardi, S. Aguggini, A. Bersiga, L. Campo, L. Dogliotti, A. Bottini and A.L. Harris, 2007. Regulation of hepatocyte growth factor activator inhibitor 2 by hypoxia in breast cancer Clin. Cancer Res., 13: 550-558. DOI: 10.1158/1078-0432.CCR-061266.
32. Gigout, L., P. Rebollo, N. Clement, K.H. Warrington, N. Muzyczka, R.M. Linden and T. Weber, 2005. Altering AAV tropism with mosaic viral capsids. Mol. Ther., 11: 856-865. http://www.ncbi.nlm.nih.gov/pubmed/15922956.

33. Giraud, C., E. Winocour and K.I. Berns, 1994. Site-specific integration by adeno-associated virus is directed by a cellular dna sequence. Proc. Natl. Acad. Sci. USA., 91: 10039-10043. http://www.pnas.org/content/91/21/10039.abstract.

34. Girod, A., M. Ried, C. Wobus, H. Lahm, K. Leike, J. Kleinschmidt, G. Deleage and M. Hallek, 1999. Genetic capsid modifications allow efficient retargeting of adeno-associated virus type 2. Nat. Med., 5: 1052-1056. DOI: 10.1038/12491.

35. Grimm, D. and M.A. Kay, 2007. Combinatorial RNAI: A winning strategy for the race against evolving targets? Mol. Ther., 15: 878-888. http://www.ncbi.nlm.nih.gov/pubmed/17311009.

36. Hajitou, A., R. Pasqualini and W. Arap, 2006. Vascular targeting: Recent advances and therapeutic perspectives. Trends Cardiovasc. Med., 16: 80-88. http://www.ncbi.nlm.nih.gov/ pubmed/16546688.

37. Halbert, C.L., A.D. Miller, S. Mcnamara, J. Emerson, R.L. Gibson, B. Ramsey and M.L. Aitken, 2006. Prevalence of neutralizing antibodies against Adeno-Associated Virus (AAV) types 2, 5 and 6 in cystic fibrosis and normal populations: Implications for gene therapy using AAV vectors. Hum. Gene Ther., 17: 440-447. http:// cat.inist.fr/?aModele $=$ afficheN\&cpsidt $=17720310$.

38. Halvorsen, O.J., K. Rostad, A.M. Oyan, H. Puntervoll, T.H. Bo, L. Stordrange, S. Olsen, S.A. Haukaas, L. Hood, I. Jonassen, K.H. Kalland and L.A. Akslen, 2007. Increased expression of SIM2-S protein is a novel marker of aggressive prostate cancer. Clin. Cancer Res., 13: 892-897. DOI: 10.1158/1078-0432.CCR-06-1207.

39. Han, W., M. Wind-Rotolo, R.L. Kirkman and C.D. Morrow, 2004. Inhibition of human immunodeficiency virus type 1 replication by sirna targeted to the highly conserved primer binding site. Virology, 330: 221-232. http://www.ncbi.nlm.nih.gov/pubmed/15527848.

40. Handa, A., S. Muramatsu, J. Qiu, H. Mizukami and K.E. Brown, 2000. Adeno-Associated Virus (AAV)-3-based vectors transduce haematopoietic cells not susceptible to transduction with AAV-2based vectors. J. Gen Virol., 81: 2077-2084. http:// vir.sgmjournals.org/cgi/content/abstract/81/8/2077.

41. Hauck, B., L. Chen and W. Xiao, 2003. Generation and characterization of chimeric recombinant AAV vectors. Mol. Ther., 7: 419-425. http://www.ncbi.nlm.nih.gov/pubmed/12668138. 
42. Hauck, B. And W. Xiao, 2003. Characterization of tissue tropism determinants of adeno-associated virus type 1. J. Virol., 77: 2768-2774. DOI: 10.1128/JVI.77.4.2768-2774.2003.

43. Hauck, B., R.R. Xu, J. Xie, W. Wu, Q. Ding, M. Sipler, H. Wang, L. Chen, J.F. Wright and W. Xiao, 2006. Efficient AAV1-AAV2 hybrid vector for gene therapy of hemophilia. Hum. Gene Ther., 17: 46-54. http://cat.inist.fr/ ?aModele $=$ afficheN\&cpsidt $=17537821$.

44. Hoffman, B.E., E. Dobrzynski, L. Wang, L. Hirao, F. Mingozzi, O. Cao and R.W. Herzog, 2007. Muscle as a target for supplementary factor IX gene transfer. Hum. Gene Ther., 18: 603-613. DOI: 10.1089/hum.2007.042.

45. Huttner, N.A., A. Girod, L. Perabo, D. Edbauer, J.A. Kleinschmidt, H. Buning and M. Hallek, 2003. Genetic modifications of the adeno-associated virus type 2 capsid reduce the affinity and the neutralizing effects of human serum antibodies. Gene Ther., 10: 2139-2147. http://cat.inist.fr/ ?aModele $=$ afficheN\&cpsidt $=15291210$.

46. Inagaki, K., S. Fuess, T.A. Storm, G.A. Gibson, C.F. Mctiernan, M.A. Kay and H. Nakai, 2006. Robust systemic transduction with AAV9 vectors in mice: Efficient global cardiac gene transfer superior to that of AAV8. Mol. Ther., 14: 45-53. http://cat.inist.fr/?aModele $=$ afficheN\&cpsidt $=1794$ 3562 .

47. Ishihara, A., T.A. Zachos, J.S. Bartlett and A.L. Bertone, 2006. Evaluation of permissiveness and cytotoxic effects in equine chondrocytes, synovial cells and stem cells in response to infection with adenovirus 5 vectors for gene delivery. Am. J. Vet. Res., 67: 1145-1155. http://www.ncbi.nlm.nih.gov/pubmed/16817735.

48. Kaludov, N., K.E. Brown, R.W. Walters, J. Zabner and J.A. Chiorini, 2001. Adeno-associated virus serotype 4 (AAV4) and AAV5 both require sialic acid binding for hemagglutination and efficient transduction but differ in sialic acid linkage specificity. J. Virol., 75: 6884-6893. DOI: 10.1128/JVI.75.15.6884-6893.2001.

49. Katano, H., M.R. Kok, A.P. Cotrim, S. Yamano, M. Schmidt, S. Afione, B.J. Baum and J.A. Chiorini, 2006. Enhanced transduction of mouse salivary glands with AAV5-based vectors. Gene Ther., 13: 594-601. http://cat.inist.fr/ ?aModele $=$ afficheN\&cpsidt $=17601429$.

50. King, J.A., R. Dubielzig, D. Grimm and J.A. Kleinschmidt, 2001. DNA helicase-mediated packaging of adeno-associated virus type 2 genomes into preformed capsids. EMBO J., 20, 3282-3291. http://www.nature.com/ emboj/journal/v20/n12/abs/7593825a.html.
51. Kotin, R.M., R.M. Linden and K.I. Berns, 1992. Characterization of a preferred site on human chromosome $19 \mathrm{q}$ for integration of adenoassociated virus dna by non-homologous recombination. EMBO J., 11: 5071-5078. http:// www.pubmedcentral.nih.gov/articlerender.fcgi?arti $\mathrm{d}=556985$.

52. Le Bec, C. and A.M. Douar, 2006. Gene Therapy progress and prospects--vectorology: Design and production of expression cassettes in AAV vectors. Gene Ther., 13: 805-813. http://cat.inist.fr/ ?aModele $=$ afficheN\&cpsidt $=17749081$.

53. Li, C., M. Hirsch, A. Asokan, B. Zeithaml, H. Ma, T. Kafri and R.J. Samulski, 2007. Adeno-associated virus type 2 (AAV2) capsid-specific cytotoxic T lymphocytes eliminate only vector-transduced cells coexpressing the AAV2 capsid in vivo. J. Virol., 81: 7540-7547. DOI: 10.1128/JVI.00529-07.

54. Li, X.C. and J.L. Zhuo, 2007. Targeting glucagon receptor signalling in treating metabolic syndrome and renal injury in type 2 diabetes: Theory versus promise. Clin. Sci. (London), 113: 183-193. http:// cat.inist.fr/?aModele $=$ afficheN\&cpsidt $=18955992$.

55. Liu, Q., C.F. Perez and Y. Wang, 2006. Efficient site-specific integration of large transgenes by an enhanced herpes simplex virus/adeno-associated virus hybrid amplicon vector. J. Virol., 80: 1672-1679. DOI: 10.1128/JVI.80.4.16721679.2006.

56. Liu, Q., K. Wu, Y. Zhu, Y. He, J. Wu and Z. Liu, 2007. Silencing MAT2A gene by rna interference inhibited cell growth and induced apoptosis in human hepatoma cells. Hepatol. Res., 37: 376-388. http://www.ncbi.nlm.nih.gov/pubmed/17441811.

57. Liu, Y., A.D. Santin, M. Mane, M. Chiriva-Internati, G.P. Parham, A. Ravaggi and P.L. Hermonat, 2000. Transduction and utility of the granulocytemacrophage colony-stimulating factor gene into monocytes and dendritic cells by adeno-associated virus. J. Interferon Cytokine Res., 20: 21-30. http://www.ncbi.nlm.nih.gov/pubmed/10670649.

58. Lu, L.L., Y. Su, C.L. Duan, C.L. Zhao, H.J. Su, J. Wu, H.Y. Zhao, Q.Y. Xu and H. Yang, 2004. Gene therapy of tyrosine hydroxylase, aromatic 1amino acid decarboxylase and GTP cyclohydrolase genes in rat model of parkinson's disease. Zhonghua Yi Xue Za Zhi, 84: 1528-1532.

59. Lux, K., N. Goerlitz, S. Schlemminger, L. Perabo, D. Goldnau, J. Endell, K. Leike, D.M. Kofler, S. Finke, M. Hallek and H. Buning, 2005. Green fluorescent protein-tagged adeno-associated virus particles allow the study of cytosolic and nuclear trafficking. J. Virol., 79: 11776-11787. DOI:10.1128/JVI.79.18.11776-11787.2005. 
60. Maheshri, N., J.T. Koerber, B.K. Kaspar and D.V. Schaffer, 2006. Directed evolution of adenoassociated virus yields enhanced gene delivery vectors. Nat. Biotechnol., 24: 198-204. DOI: 10.1038/nbt1182.

61. Martin, K.R., R.L. Klein and H.A. Quigley, 2002. Gene delivery to the eye using adeno-associated viral vectors. Methods, 28: 267-275. http://www.ncbi.nlm.nih.gov/pubmed/12413426.

62. Mccarthy, H.O., J.A. Coulter, J. Worthington, T. Robson and D.G. Hirst, 2007. Human osteocalcin: A strong promoter for nitric oxide synthase gene therapy, with specificity for hormone refractory prostate cancer. J. Gene Med., 9: 511-520. http://www3.interscience.wiley.com/journal/114229 315/abstract?CRETRY $=1 \&$ SRETRY $=0$.

63. Mccarty, D.M., S.M. Young and R.J. Samulski, 2004. Integration of Adeno-Associated Virus (AAV) and recombinant AAV vectors. Annu. Rev. Genet., 38: 819-845. DOI: 10.1146/annurev.genet.37.110801.143717.

64. Mcpherson, R.A., L.J. Rosenthal and J.A. Rose, 1985. Human cytomegalovirus completely helps adeno-associated virus replication. Virology, 147: 217-222. http://www.ncbi.nlm.nih. gov/pubmed/2998066.

65. Milas, M., D. Yu, A. Lang, T. Ge, B. Feig, A.K. ElNaggar and R.E. Pollock, 2000. Adenovirusmediated p53 gene therapy inhibits human sarcoma tumorigenicity. Cancer Gene Ther., 7: 422-429. http://www.nature.com/cgt/journal/v7/n3/abs/7700 141a.html.

66. Miller, D.G., E.A. Rutledge and D.W. Russell, 2002. Chromosomal effects of adeno-associated virus vector integration. Nat. Genet., 30: 147-148. http://www.ncbi.nlm.nih.gov/pubmed/11799395.

67. Miller, D.G., P.R. Wang, L.M. Petek, R.K. Hirata, M.S. Sands and D.W. Russell, 2006. Gene targeting in vivo by adeno-associated virus vectors. Nat. Biotechnol., 24: 1022-1026. DOI: 10.1038/nbt1231.

68. Mori, S., T. Takeuchi, Y. Enomoto, K. Kondo, K. Sato, F. Ono, N. Iwata, T. Sata and T. Kanda, 2006. Biodistribution of a low dose of intravenously administered AAV-2, 10 and 11 vectors to cynomolgus monkeys. Jap. J. Infect. Dis., 59: 285-293. http://cat.inist.fr/ ?aModele $=$ afficheN\&cpsidt $=18343229$.

69. Muller, O.J., B. Leuchs, S.T. Pleger, D. Grimm, W.M. Franz, H.A. Katus and J.A. Kleinschmidt, 2006. Improved cardiac gene transfer by transcriptional and transductional targeting of adeno-associated viral vectors. Cardiovasc. Res., 70:70-78.

http://cat.inist.fr/ ?aModele=afficheN\&cpsidt=17650796.
70. Nicklin, S.A. and A.H. Baker, 2002. Tropismmodified adenoviral and adeno-associated viral vectors for gene therapy. Curr. Gene. Ther., 2: 273-293. http://www.ncbi.nlm.nih.gov/ pubmed/12189716.

71. Nozaki, S., Y. Endo, H. Nakahara, K. Yoshizawa, T. Ohara and E. Yamamoto, 2006. Targeting urokinase-type plasminogen activator and its receptor for cancer therapy. Anticancer Drugs, 17: 1109-1117. http://cat.inist.fr/ ?aModele $=$ afficheN\&cpsidt $=18259417$.

72. Paraskevakou, G., C. Allen, T. Nakamura, P. Zollman, C.D. James, K.W. Peng, M. Schroeder, S.J. Russell and E. Galanis, 2007. Epidermal Growth Factor Receptor (EGFR)-retargeted measles virus strains effectively target EGFR-or EGFRVIII expressing gliomas. Mol. Ther., 15: 677-686. http://www.ncbi.nlm.nih.gov/pubmed/17299404.

73. Passini, M.A., D.J. Watson, CH. Vite, D.J. Landsburg, A.L. Feigenbaum and J.H. Wolfe, 2003. Intraventricular brain injection of adeno-associated virus type 1 (AAV1) in neonatal mice results in complementary patterns of neuronal transduction to AAV2 and total long-term correction of storage lesions in the brains of beta-glucuronidase-deficient mice. J. Virol., 77: 7034-7040. http://www.ncbi.nlm.nih.gov/pubmed/12768022.

74. Poulsen, D.J., D. Standing, K. Bullshields, K. Spencer, P.E. Micevych and A.M. Babcock, 2007. Overexpression of hippocampal $\mathrm{Ca} 2+/$ calmodulin-dependent protein kinase II improves spatial memory. J. Neurosci. Res., 85: 735-739. http://cat.inist.fr/ ?aModele $=$ afficheN\&cpsidt $=18552145$.

75. Qing, K., C. Mah, J. Hansen, S. Zhou, V. Dwarki and A. Srivastava, 1999. Human fibroblast growth factor receptor 1 is a co-receptor for infection by adeno-associated virus 2. Nat. Med., 5: 71-77. DOI: $10.1038 / 4758$.

76. Rabinowitz, J.E., D.E. Bowles, S.M. Faust, J.G. Ledford, S.E. Cunningham and R.J. Samulski, 2004. Cross-dressing the virion: The transcapsidation of adeno-associated virus serotypes functionally defines subgroups. J. Virol., 78: 4421-4432. DOI: 10.1128/JVI.78.9.44214432.2004.

77. Rabinowitz, J.E., F. Rolling, C. Li, H. Conrath, W. Xiao, X. Xiao and R.J. Samulski, 2002. Crosspackaging of a single Adeno-Associated Virus (AAV) type 2 vector genome into multiple AAV serotypes enables transduction with broad specificity.J.Virol.,76:791-801.

http://www.ncbi.nlm.nih.gov/pubmed/11752169. 
78. Rabinowitz, J.E., W. Xiao and R.J. Samulski, 1999. Insertional mutagenesis of AAV2 capsid and the production of recombinant virus. Virology, 265: 274-285. http://www.ncbi.nlm.nih.gov/ pubmed/10600599.

79. Recchia, A., R.J. Parks, S. Lamartina, C. Toniatti, L. Pieroni, F. Palombo, G. Ciliberto, F.L. Graham, R. Cortese, N. La Monica and S. Colloca, 1999. Site-specific integration mediated by a hybrid adenovirus/adeno-associated virus vector. Proc. Natl. Acad. Sci. USA., 96: 2615-2620. http://www.pubmedcentral.nih.gov/articlerender.fc gi? artid $=15817$.

80. Ren, C., A.F. White and S. Ponnazhagan, 2007. Notch1 augments intracellular trafficking of adenoassociated virus type 2. J. Virol., 81: 2069-2073. DOI: 10.1128/JVI.01811-06.

81. Russell, D.W. and R.K. Hirata, 1998. Human gene targeting by viral vectors. Nat. Genet., 18: 325-330. http://www.ncbi.nlm.nih.gov/pubmed/9537413.

82. Sathornsumetee, S. and J.N. Rich, 2006. New treatment strategies for malignant gliomas. Expert Rev. Anticancer Ther., 6: 1087-1104. http:// cat.inist.fr/?aModele=afficheN\&cpsidt=17931244.

83. Schmidt, M., S. Afione and R.M. Kotin, 2000. Adeno-associated virus type 2 rep78 induces apoptosis through caspase activation independently of p53. J. Virol., 74: 9441-9450. http://jvi.asm.org/cgi/content/abstract/74/20/9441.

84. Seiler, M.P., A.D. Miller, J. Zabner and C.L. Halbert, 2006. Adeno-associated virus types 5 and 6 use distinct receptors for cell entry. Hum. Gene Ther., 17: 10-19. http://cat.inist.fr/ ?aModele $=$ afficheN\&cpsidt $=17537818$.

85. Shayakhmetov, D.M., C.A. Carlson, H. Stecher, Q. Li, G. Stamatoyannopoulos and A. Lieber, 2002. A high-capacity, capsid-modified hybrid adenovirus/ adeno-associated virus vector for stable transduction of human hematopoietic cells. J. Virol., 76: 11351143. DOI: 10.1128/JVI.76.3.1135-1143.2002.

86. Shevtsova, Z., J.M. Malik, U. Michel, M. Bahr and S. Kugler, 2005. Promoters and serotypes: targeting of adeno-associated virus vectors for gene transfer in the rat central nervous system in vitro and in vivo. Exp. Physiol., 90: 53-59. DOI: 10.1113/expphysiol.2004.028159.

87. Shi, W., G.S. Arnold and J.S. Bartlett, 2001. Insertional mutagenesis of the adeno-associated virus type 2 (AAV2) capsid gene and generation of AAV2 vectors targeted to alternative cell-surface receptors. Hum. Gene Ther., 12: 1697-1711. http:// cat.inist.fr/?aModele=afficheN\&cpsidt=14141561.
88. Shi, W. and J.S. Bartlett, 2003. RGD inclusion in vp3 provides adeno-associated virus type 2 (AAV2)-based vectors with a heparan sulfateindependent cell entry mechanism. Mol. Ther., 7: $\quad 515-525$. http://www.ncbi.nlm.nih.gov/ pubmed/12727115.

89. Shi, W., A. Hemminki and J.S. Bartlett, 2006. Capsid modifications overcome low heterogeneous expression of heparan sulfate proteoglycan that limits AAV2-mediated gene transfer and therapeutic efficacy in human ovarian carcinoma. Gynecol. Oncol., 103: 1054-1062. http://www.ncbi.nlm.nih.gov/pubmed/16870238.

90. Shi, X., G. Fang, W. Shi and J.S. Bartlett, 2006. Insertional mutagenesis at positions 520 and 584 of adeno-associated virus type 2 (AAV2) capsid gene and generation of AAV2 vectors with eliminated heparin- binding ability and introduced novel tropism. Hum. Gene Ther., 17: 353-361.

91. Stachler, M.D. and J.S. Bartlett, 2006. Mosaic vectors comprised of modified aav1 capsid proteins for efficient vector purification and targeting to vascular endothelial cells. Gene Ther., 13: 926-931. DOI: $10.1038 /$ sj.gt.3302738.

92. Streck, C.J., J. Zhou, C.Y. Ng, Y. Zhang, A.C. Nathwani and A.M. Davidoff, 2004. Longterm recombinant adeno-associated, virusmediated, liver-generated expression of an angiogenesis inhibitor improves survival in mice with disseminated neuroblastoma. J. Am. Coll. Surg., 199: 78-86. http://www.ncbi.nlm.nih. gov/pubmed/15217634.

93. Su, P.F., S.Y. Chiang, C.W. Wu and F.Y. Wu, 2000. Adeno-associated virus major rep78 protein disrupts binding of tata-binding protein to the $\mathrm{p} 97$ promoter of human papillomavirus type 16. J. Virol., 74: 2459-2465. http://www.ncbi.nlm. nih.gov/pubmed/10666281.

94. Summerford, C., J.S. Bartlett and R.J. Samulski, 1999. Alphavbeta5 integrin: A co-receptor for adeno-associated virus type 2 infection. Nat. Med., 5: $\quad$ 78-82. $\quad$ http://www.ncbi.nlm.nih. gov/pubmed/9883843.

95. Summerford, C. and R.J. Samulski, 1998. Membrane-associated heparan sulfate proteoglycan is a receptor for adeno-associated virus type 2 virions. J. Virol., 72: 1438-1445. http://jvi.asm.org/ cgi/content/abstract/72/2/1438.

96. Sung, S.Y., C.L. Hsieh, D. Wu, L.W. Chung and P.A. Johnstone, 2007. Tumor microenvironment promotes cancer progression, metastasis and therapeutic resistance. Curr. Probl. Cancer, 31: 36-100. http://www.ncbi.nlm.nih. gov/pubmed/17362788. 
97. Surosky, R.T., M. Urabe, S.G. Godwin, S.A. Mcquiston, G.J. Kurtzman, K. Ozawa and G. Natsoulis, 1997. Adeno-associated virus rep proteins target DNA sequences to a unique locus in the human genome. J. Virol., 71: 7951-7959. http://jvi.asm.org/cgi/content/abstract/71/10/7951.

98. Sutanto, E.N., D. Zhang, Y.K. Lai, W.Y. Shen and P.E. Rakoczy, 2006. Potential use of cellular promoter(s) to target rpe in AAV-mediated delivery. Cellular promoters and RPE-targeting. Adv. Exp. Med. Biol., 572: 267-273. http://www. ncbi.nlm.nih.gov/pubmed/17249583.

99. Suwelack, D., A. Hurtado-Lorenzo, E. Millan, V. Gonzalez-Nicolini, K. Wawrowsky, P.R. Lowenstein and M.G. Castro, 2004. Neuronal expression of the transcription factor Glil using the talphal alpha-tubulin promoter is neuroprotective in an experimental model of parkinson's disease. Gene Ther., 11: 1742-1752. http://www. ncbi.nlm.nih.gov/pubmed/15573088.

100.Tan, M., K. Qing, S. Zhou, M.C. Yoder and A. Srivastava, 2001. Adeno-associated virus 2mediated transduction and erythroid lineagerestricted long-term expression of the human betaglobin gene in hematopoietic cells from homozygous beta-thalassemic mice. Mol. Ther., 3: 940-946. http://www.ncbi.nlm.nih. gov/pubmed/17249583.

101.Thomas, C.E., T.A. Storm, Z. Huang and M.A. Kay, 2004. Rapid uncoating of vector genomes is the key to efficient liver transduction with pseudotyped adeno-associated virus vectors. J. Virol., 78:3110-3122.

DOI: 10.1128/JVI.78.6.3110-3122.2004.

102. Vandenberghe, L.H., L. Wang, S. Somanathan, Y. Zhi, J. Figueredo, R. Calcedo, J. Sanmiguel, R.A. Desai, C.S. Chen, J. Johnston, R.L. Grant, G. Gao and J.M. Wilson, 2006. Heparin binding directs activation of $\mathrm{T}$ cells against adenoassociated virus serotype 2 capsid. Nat. Med., 12: 967-971. DOI: 10.1038/nm1445.

103. Vandendriessche, T., L. Thorrez, A. AcostaSanchez, I. Petrus, L. Wang, L. Ma, L. de Waele, Y. Iwasaki, V. Gillijns, J.M. Wilson, D. Collen and M.K. Chuah, 2007. Efficacy and safety of adenoassociated viral vectors based on serotype 8 and 9 vs. lentiviral vectors for hemophilia $b$ gene therapy. J. Thromb. Haemost., 5: 16-24. http://www.ncbi.nlm.nih.gov/pubmed/17002653.

104. Vasileva, A. and R. Jessberger, 2005. Precise hit: Adeno-associated virus in gene targeting. Nat. Rev. Microbiol., 3: 837-847. http://www.ncbi. nlm.nih.gov/pubmed/16261169.
105. Veron, P., V. Allo, C. Riviere, J. Bernard, A.M. Douar and C. Masurier, 2007. Major subsets of human dendritic cells are efficiently transduced by self-complementary adeno-associated virus vectors 1 and 2. J. Virol., 81: 5385-5394. DOI: 10.1128/JVI.02516-06.

106. Volpers, C., C. Thirion, V. Biermann, S. Hussmann, H. Kewes, P. Dunant, H. Von Der Mark, A. Herrmann, S. Kochanek and H. Lochmuller, 2003. Antibody-mediated targeting of an adenovirus vector modified to contain a synthetic immunoglobulin G-binding domain in the capsid. J. Virol., 77: 2093-2104. DOI: 10.1128/JVI.77.3.2093-2104.2003.

107.Walters, R.W., J.M. Pilewski, J.A. Chiorini and J. Zabner, 2002. Secreted and transmembrane mucins inhibit gene transfer with AAV4 more efficiently than AAV5. J. Biol. Chem., 277: 23709-23713. http://www.jbc.org/cgi/ content/abstract/277/26/23709.

108.Walters, R.W., S.M.Yi, S. Keshavjee, K.E. Brown, M.J. Welsh, J.A. Chiorini and J. Zabner, 2001. Binding of adeno-associated virus type 5 to 2,3linked sialic acid is required for gene transfer. J. Biol. Chem., 276: 20610-20616. http://www.ncbi.nlm.nih.gov/pubmed/11262413.

109. Walz, C. and J.R. Schlehofer, 1992. Modification of some biological properties of hela cells containing adeno-associated virus dna integrated into chromosome 17. J. Virol., 66: 2990-3002. http://jvi.asm.org/cgi/content/abstract/66/5/2990.

110. Wang, H., D.M. Shayakhmetov, T. Leege, M. Harkey, Q. Li, T. Papayannopoulou, G. Stamatoyannopolous and A. Lieber, 2005. A capsid-modified helper-dependent adenovirus vector containing the beta-globin locus control region displays a nonrandom integration pattern and allows stable, erythroid-specific gene expression. J. Virol., 79: 10999-11013. http://jvi.asm.org/cgi/content/abstract/66/5/2990.

111. Wang, L., J. Figueredo, R. Calcedo, J. Lin and J.M. Wilson, 2007. Cross-presentation of adenoassociated virus serotype 2 capsids activates cytotoxic $\mathrm{T}$ cells but does not render hepatocytes effective cytolytic targets. Hum. Gene Ther., 18: 185-194. http://cat.inist.fr/ ?aModele $=$ afficheN\&cpsidt $=18973292$.

112. Watson, G., J. Bastacky, P. Belichenko, M. Buddhikot, S. Jungles, M. Vellard, W.C. Mobley and E. Kakkis, 2006. Intrathecal administration of AAV vectors for the treatment of lysosomal storage in the brains of MPS I mice. Gene Ther., 13: 917-925. http://cat.inist.fr/ ?aModele $=$ afficheN\&cpsidt $=17756328$. 
113. Wei, Y., D. Wang, F. Topczewski and M.J. Pagliassotti, 2007. Fructose-mediated stress signaling in the liver: Implications for hepatic insulin resistance. J. Nutr. Biochem., 18: 1-9. http:// cat.inist.fr/?aModele $=$ afficheN\&cpsidt $=19004987$.

114. White, A.F. and S. Ponnazhagan, 2006. Airway epithelium directed gene therapy for cystic fibrosis. Med. Chem., 2: 499-503. http://www. ingentaconnect.com/content/ben/mc/2006/0000000 2/00000005/art00008.

115. White, S.J., S.A. Nicklin, H. Buning, M.J. Brosnan, K. Leike, E.D. Papadakis, M. Hallek and A.H. Baker, 2004. Targeted gene delivery to vascular tissue in vivo by tropism-modified adenoassociated virus vectors. Circulation, 109: 513-519. http://www.ncbi.nlm.nih.gov/pubmed/14732747.

116. Won, Y.S. and S.W. Lee, 2007. Targeted retardation of hepatocarcinoma cells by specific replacement of alpha-fetoprotein RNA. J. Biotechnol., 129: 614-619. http://cat.inist.fr/ ?aModele $=$ afficheN\&cpsidt $=18748060$.

117.Wu, Z., E. Miller, M. Agbandje-Mckenna and R.J. Samulski, 2006. Alpha2,3 and alpha2,6 Nlinked sialic acids facilitate efficient binding and transduction by adeno-associated virus types 1 and 6. J. Virol., 80: 9093-9103. http://www.ncbi. nlm.nih.gov/pubmed/16940521.

118. Xiao, W., K.H. Warrington, P. Hearing, J. Hughes and N. Muzyczka, 2002. Adenovirus-facilitated nuclear translocation of adeno-associated virus type 2. J. Virol., 76: 11505-11517. DOI: 10.1128/JVI.76.22.11505-11517.2002.

119.Xiao, X., j. Li, T.J. Mccown and R.J. Samulski, 1997. Gene transfer by adeno-associated virus vectors into the central nervous system. Exp. Neurol., 144: 113-124. http://www.ncbi.nlm.nih. gov/pubmed/9126160.

120. Yamamoto, N., M. Suzuki, M.A. Kawano, T. Inoue, R.U. Takahashi, H. Tsukamoto, T. Enomoto, Y. Yamaguchi, T. Wada and H. Handa, 2007. Adeno-associated virus site-specific integration is regulated by TRP-185. J. Virol., 81: 1990-2001. http://jvi.asm.org/cgi/reprint/81/4/1990.pdf.

121. Yang, Q., M. Mamounas, G. Yu, S. Kennedy, B. Leaker, J. Merson, F. Wong-Staal, M. Yu and J.R. Barber, 1998. Development of novel cell surface Cd34-targeted recombinant adenoassociated virus vectors for gene therapy. Hum. Gene Ther., 9: 1929-1937. http://www.ncbi.nlm.nih.gov/pubmed/9741431.
122. You, H., Y. Liu, C.K. Prasad, N. Agrawal, D. Zhang, S. Bandyopadhyay, H. Liu, H.H. Kay, J.L. Mehta and P.L. Hermonat, 2006. Multiple human papillomavirus genes affect the adenoassociated virus life cycle. Virology, 344: 532-540. http://www.ncbi.nlm.nih.gov/pubmed/16203022.

123. Young, S.M. and R.J. Samulski, 2001. AdenoAssociated Virus (AAV) site-specific recombination does not require a rep-dependent origin of replication within the AAV terminal repeat. Proc. Natl. Acad. Sci. USA., 98: 13525-13530. http://www.pnas.org/content/98/24/13525.abstract.

124.Zabner, J., M. Seiler, R. Walters, R.M. Kotin, W. Fulgeras, B.L. Davidson and J.A. Chiorini, 2000. Adeno-associated virus type 5 (AAV5) but not AAV2 binds to the apical surfaces of airway epithelia and facilitates gene transfer. J. Virol., 74: 3852-3858. http://jvi.asm.org/cgi/content/ abstract/74/8/3852.

125.Zhan, D., A.D. Santin, Y. Liu, G.P. Parham, C. Li, C. Meyers and P.L. Hermonat, 1999. Binding of the human papillomavirus type $16 \mathrm{p} 97$ promoter by the adeno-associated virus rep78 major regulatory protein correlates with inhibition. J. Biol. Chem., 274: 31619-31624. http://www.jbc.org/ cgi/content/abstract/274/44/31619.

126.Zhang, C., N.G. Cortez and K.I. Berns, 2007. Characterization of a bipartite recombinant adenoassociated viral vector for site-specific integration. Hum. Gene. Ther., 18: 787-797. http://cat. inist.fr/?aModele $=$ afficheN\&cpsidt $=19101975$.

127.Zhang, H.Z., Y. Wang, P. Gao, F. Lin, L. Liu, B. Yu, J.H. Ren, H. Zhao and R. Wang, 2006. Silencing stathmin gene expression by survivin promoter-driven sirna vector to reverse malignant phenotype of tumor cells. Cancer Biol. Ther., 5: 1457-1461. http://www.ncbi.nlm. nih.gov/pubmed/17012855.

128.Zhong, L., W. Zhao, J. Wu, N. Maina, Z. Han and A. Srivastava, 2006. Adeno-associated virusmediated gene transfer in hematopoietic stem/ progenitor cells as a therapeutic tool. Curr. Gene Ther., 6: 683-698. http://cat.inist.fr/ ?aModele $=$ afficheN\&cpsidt $=18364515$. 